\title{
Establishing Level-Area-Volume Relationships of Darawat Reservoir Using Time Series Remote- Sensing Images
}

\section{Fahad Hameed}

National Center for Remote Sensing \& Geo-Informatics, Institute of Space Technology, Karachi

Muhammad Ateeq Qureshi ( $\square$ atqureshi_pk@yahoo.com )

National Center for Remote Sensing \& Geo-Informatics, Institute of Space Technology, Karachi

Rao Muhammad Zahid Khalil

National Center for Remote Sensing \& Geo-Informatics, Institute of Space Technology, Karachi

\section{Research Article}

Keywords: Water reservoir, Remote sensing, MNDWI, DEM, Level-area-volume relationship

Posted Date: January 31st, 2022

DOI: https://doi.org/10.21203/rs.3.rs-1237194/v1

License: (c) (i) This work is licensed under a Creative Commons Attribution 4.0 International License.

Read Full License 


\section{Abstract}

The study aims to determine the level-area-volume relationship for the newly constructed Darawat reservoir on non-perennial channels located in the Kirthar National park in Jamshoro district of Sindh, Pakistan. Landsat-8, Digital Elevation Model (DEM), Modified Normalized Difference Water Index (MNDWI), and In-situ data, were used. A set of equations represented the relationship between three parameters (Level-area-volume) derived from five different models (exponential, linear, logarithmic, polynomial, and power). Results showed a significant relationship in Level-area-volume. The coefficient of determination showed relationships for water level-surface area range from 0.941 to 0.991 , for water level-volume a range reflected from 0.943 to 0.998 , and for area-volume represented a range from 0.928 to 0.994 . The study estimated results validated by the percentage difference (PD), the root means square error (RMSE), and coefficient of determination $\left(\mathrm{R}^{2}\right)$ using surface areas of the year 2019 and in-situ water levels. Power model relatively showed the best results, $P D=0.227$, $R M S E=0.335$, and $R^{2}=0.982$. The study suggests the remote sensing techniques may utilize, if pre-constructed bathymetry data is available, to estimate level-area-volume relationships for rainwater resources management, flood control, and environmental monitoring.

\section{Introduction}

Water is a natural resource that cannot be created but only be conserved. This resource is only conserved through the construction of dams and reservoirs (Qureshi 2010). Water reservoirs are built for several reasons, mainly to generate hydroelectricity, flood control, drinkable, irrigation, recreation, water quality, and quantity management. The population in the semi-arid region depends on non-perennial channels water reservoirs to enhance livelihood opportunities (Annor et al. 2009). Water storage in reservoirs allowed them to irrigate agriculture throughout the year and minimized water scarcities during a drought season. The dams also have a remarkable effect on downstream discharge, as they can delay flooding and weaken floods by accumulating surplus water (Poolman 2005). Water reservoirs can have a positive impact on the hydrological process in surrounding areas (Rodrigues and Liebe 2013; Rodrigues et al. 2012). Real-time monitoring and management of these reservoirs are essential due to their significant socio-economic and environmental importance (Pipitone et al. 2018).

Dams/reservoir levels and their volume are susceptible to change in the environment, and their variations can disturb the feasible usage of localized water resources (Zheng et al. 2016). Therefore, the calculation of water surface levels and their area is vital for monitoring height-area-volume variations. Water levelarea-volume relationships are the most primary indicators of dam/reservoir and can use for routing of the flood, dam/reservoir operations, water surface area determination, volume level elevation. As a result, creating the water level-volume-reservoir area equations are of great practical significance (Haghiabi et al. 2013).

The lack of technical information such as level-area-volume about the small reservoir can endanger agriculture sustainability and affect the farmers' livelihood. Although, the level-area-volume relationship 
is vital evidence for water resource planning and management. The existing capacities of water reservoirs must be accurately known for efficiently managing and monitoring usages of water optimally (Annor et al. 2009). However, it is laborious, time-consuming, extensive field surveys, and not easy to use conventional in-situ hydrologic computation to predict relevant information of the reservoir for a long duration.

Three approaches are generally employed to monitor water bodies. Firstly, the in-situ measurement and bathymetry. The volume of water is not measured directly in dams and reservoirs. Usually, the amount of water storage in the dams/reservoirs is measured through in-situ and bathymetry maps. A bathymetry chart is developed by using sonar sensors mounted on vessels to determine the sub-aquatic topography. The second, the model methods. Models are also the abstraction of actual phenomena and give only estimates. The accuracy depends on calibration. Model calibration and validation again required highaccuracy in-situ data. The third is remote sensing. It used far and wide extensively (Duan and Bastiaanssen 2013; Jeppesen et al. 2009). Remote sensing observations through various sensors including optical, infrared, thermal, radar (SAR), laser, and lidar mounted on different satellites based on their need. The remote sensing imagery provides the opportunity to calculate the reservoir surface extent, statistical and spatial distribution. Laser satellite and altimetry radar can measure exposed lake water surface levels (Duan and Bastiaanssen 2013). The satellite altimeters laser and radar both are profiling devices that make measurements on their ground tracks (Alsdorf et al. 2007; Birkett and Beckley 2010; Jeppesen et al. 2009). Water levels of rivers, inland seas, wetlands, and lakes are derived effectively using satellite radar altimetry (Calmant et al. 2008; Crétaux and Birkett 2006; Jeppesen et al. 2009). The satellite laser altimeter (ICESat) can calculate along-track at a footprint of $70 \mathrm{~m}$ with $172 \mathrm{~m}$ intervals (Zwally et al. 2002). The altimeters laser forward scattering to produce errors from centimeters to meters for range measurement (Brenner et al. 2007). Therefore, we used a method combining in-situ measurements of water levels of study reservoir with Digital Elevation Model (DEM) in conjunction with Landsat imagery to model the variation in Water Height-Area-Volume Curves.

\section{Study Area}

The study site of Darawat reservoir (latitude $25^{\circ} 24^{\prime} 33.4^{\prime \prime} \mathrm{N}$ and longitude $67^{\circ} 56^{\prime} 33.3^{\prime \prime} \mathrm{E}$ ) is a Concrete Gravity Dam located near village Jhangri $20 \mathrm{~km}$ from Super Highway, about $70 \mathrm{~km}$ west of Hyderabad and $135 \mathrm{~km}$ northwest of Karachi across Nai Baran River in Thatta/Jamshoro districts of Sindh Province. It is close to the Game Reserves area in the Kirthar Protected Area Complex (KPAC) (Begum et al. 2014) of the Kirthar national park (Figure 1). The watershed of Darawat is consists of low rock-strewn mountain ranges with elevation extending from 80 to $1100 \mathrm{~m}$ above mean sea level. The area of approximately $3000 \mathrm{~km}^{2}$ is generally barren land with sparse vegetation at various locations. A combination of shales sandstone limestones is found abundantly in the watershed flushed by a Baran Nadi, a branch of the great River Indus. Soils of the low-lying lands are sandy, disjointed and scrappy, but are thin to nonexistent on the highlands (Enright et al. 2005). 
The study area has no single weather station. Hyderabad and Karachi are the nearby stations. Therefore, the Climate Research Unit (CRU) dataset (version TS 4.04) for precipitation and temperature were used. The data is available on high-resolution $\left(0.5 \times 0.5^{\circ}\right)$ grid-based archives based on world meteorological stations. The dataset of CRU from 1901 to 2019 was available on 24 April 2020 by Climate Research Unit (CRU) (https://crudata.uea.ac.uk/cru/data/hrg/). The mean yearly precipitations range between 162.37 $\mathrm{mm}$. The average yearly temperature is around 26 degrees Celsius (Figure 2). The predictability of annual precipitation is low (Figure 3 ) and is mostly expected during the monsoon season from June till September.

\subsection{Data acquisition}

Landsat (OLI) series with $30 \mathrm{~m}$ spatial resolution and Sentinel's Multispectral Instrument (MSI) sensors were selected as primary data sources. Daily water levels, measured at 08:00 PST hours from September 2016 to September 2019, were acquired from the management of Darawat reservoir. Consequently, the cloud-free fifty-six Landsat images (path/row 152/42) and forty-five Sentinel 2 images from USGS (http://earthexplorer.usgs.gov) web-portal and Copernicus Hub (https://scihub.copernicus.eu) were downloaded.

\subsection{Surface water area estimation}

Water surface information is extracted by utilizing spectral water indices, density slicing, supervised or unsupervised classification (Du et al. 2014). Generally, water bodies are detected through unsupervised and supervised classification approaches. However, spectral indices detected Land surface bodies better than density slicing of a single band ( $\mathrm{Li}$ et al. 2013). Although, these approaches are very reliant on the information of the local zone personal expertise. The quick and consistent abstraction of water information may represent difficulties when classification approaches are used (Ouma and Tateishi 2006; $\mathrm{Xu}$ 2006). The normalized difference water index (NDWI) and Modified NDWI (MNDWI) are spectral indices, which can extract water bodies more precisely, swiftly, and effortlessly than classification approaches (Li et al. 2013). The MNDWI indicated that the assessing water surface area from OLI images accomplished well than the NDWI (Du et al. 2014; Ji et al. 2009; Li et al. 2013). Consequently, this study carefully used the MNDWI as the prime tool for assessment.

The specific SWIR band designated from each series of Landsat is important to MNDWI calculation. MNDWI is ideal for water surface assessment by utilizing Landsat tiles of the green $(0.53-0.59 \mu \mathrm{m})$ band

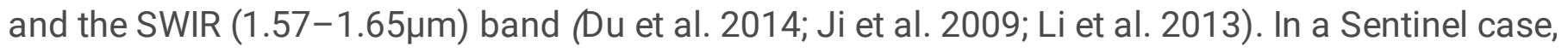
MNDWI used a green band $(559.8 \mu \mathrm{m})$ and a SWIR band $(1613.7 \mu \mathrm{m})$ for assessment of water area. Therefore, MNDWIs extracted through Landsat and Sentinel images from the succeeding formulas:

$M N D W I_{O L I}=\left(\frac{B 3_{O L I}-B 6_{O L I}}{B 3_{O L I}+B 6_{O L I}}\right)$ 
$M N D W I_{S L I}=\left(\frac{B 3_{S L I}-B 11_{S L I}}{B 3_{S L I}+B 11_{S L I}}\right)(2)$

Where $B 3_{O L I}, B 6_{O L I}$ are the Landsat OLI satellite image band number 3 and 6 . Whereas, $B 3_{S L I} B 11_{S L I}$ are the Sentinel satellite images band numbers 3 and 11.

The threshold selection in the MNDWI acts as a vital function in assessing water surface area (Du et al. 2014). The MNDWI threshold value was initially fixed to zero (Xu 2006). Alteration in threshold can specifically delineate more water bodies precisely (Ji et al. 2009). Consequently, the values of indices are set to $0.2,0.1$, and 0 as per particular image interpretation after different thresholds with various remote sensing images were evaluated. The choice of their values had no considerable influence on the results of this study, as these indices settled well in representing the optimum thresholds. The purpose of the MNDWI threshold is a subpixel fraction of vegetation and soil, usually intensifies with vegetation segment value (Ji et al. 2009; Zhang et al. 2017). The MNDWI used raw quantized calibrated pixel value as 81 for OLI and MSI images based on equations 1 and 2 with the help of GEE. The water surface areas from September 2016 to September 2019 were calculated.

\section{Material And Methods}

\subsection{Volume estimation}

The ArcGIS Surface Volume module and raster DEM were utilized for the calculation of the reservoir water volume. The capacity of water is calculated based on Lu et al. (2013), the relative surface, and base height or reference level.

$$
V=\sum_{i=1}^{n} \frac{S i\left(h_{i}+h_{i}+1+h_{i}+2\right)}{3}
$$

where the volume total $\left(\mathrm{m}^{3}\right)$ is $V$, the area projected $\left(\mathrm{m}^{2}\right)$ is Si of the submerged land on the surface of the water, distance $(m)$ are $h_{i}, h_{i}+1$, and $h_{i}+2$, the submerged of water, and $n$ is the number of triangular grids (Lu et al. 2013).

\subsection{Reservoir Level-Area-Volume relationship Curve Fitting}

Linear, power, exponential, polynomial, and logarithmic models were used to determine the relationship between water surface area and the water level (Ling et al. 2012; Zhu et al. 2014). Five models are used to identify the relationship between water surface area computed from Landsat images, in-situ water levels acquired by WAPDA, and Volume estimated using bathymetry of the reservoir. Therefore, the optimal connection among them finds.

The linear trend line is the finest used with linear data sets when the data points in a chart bar and resemblance to a straight line. Characteristically, a linear function defines a constant increase or decrease 
over time. The least-squares equation is used to pursue the slope and intercept coefficients such as:

$y=b x+a(4)$

Where the trend line slope is $b$. The intercept-y is a. the projected-y mean-value where $x$ variables are equal to 0 .

The exponential model is a line that demonstrates the values of data at an increasing rate. Consequently, it is extra curved at one side. For this model,

$y=a e^{b x}(5)$

Where calculated coefficients are $a$, and b. e is the mathematical constant (the natural logarithm base). The logarithmic line is generally used to plot data on the chart, and represented increases or decreases and then levels off containing both negative and positive values. The logarithmic model equation is:

$y=a * \ln (x)+b(6)$

Where constants are $\mathrm{a}$ and $\mathrm{b}$ and the natural logarithm function is $\ln$.

The trendline of polynomial curvilinear suits fine with oscillating values of huge data sets having greater than one up and down. Normally, it is classified by the largest exponent degree. The trendline equation of polynomial used is:

$y=b_{6} x^{6}+\cdots+b_{2} x^{2}+b_{1} x+a(7)$

Where constants are b1...b6 and a. It depends on the degree of your polynomial trend line which is one of the succeeding groups of formulas that can be used to get the constant.

Quadratic (2nd order) polynomial Equation:

$y=b_{2} x^{2}+b_{1} x+a(8)$

Cubic (3rd order) polynomial Equation:

$y=b_{3} x^{3}+b_{2} x^{2}+b_{1} x+a(9)$

The same pattern can be used to shape the formula for higher-degree polynomial trend lines. The power trend line and the exponential curve are very similar to each other, but only the later curve has a more symmetrical arc normally used to plot quantities that rises at a firm rate. A power trend line is plotted on the succeeding equation:

$y=a x^{b}(10)$

Where constants are $a$ and $b$. For consistency, the same data values can be used for all the models. The water level, surface area, and volume relationship are determined through above mention models to find 


\subsection{Accuracy assessment}

The percentage difference (PD), the root means square errors (RMSE), and the coefficient of determination $\left(R^{2}\right)$ was calculated for validation.

$P D=\frac{(\text { estimatedvalue }- \text { Insituvalue })}{\text { Insituvalue }}$

The model performance can quantify by the coefficient of determination $\left(R^{2}\right)$ using the regression equation.

$R M S E=\sqrt{\frac{1}{n} \sum_{i=1}^{n}\left(y_{i-} \hat{\mathrm{y}}_{i}\right)^{2}}(12)$

Where yi is the in-situ measurement of water level, $\hat{y}_{i}$ is the estimated representing values using the approaches explained in this study, $\mathrm{i}$ is the ith observation, and $\mathrm{n}$ is the number of observations.

$R^{2}=\frac{\sum_{i=1}^{n}\left(y_{i-} \hat{\mathrm{y}}_{i}\right)^{2}}{\sum_{i=1}^{n}\left(y_{i-} \hat{\mathrm{y}}_{i}\right)^{2}}=1-\frac{\sum_{i=1}^{n}\left(y_{i-} \hat{\mathrm{y}}_{i}\right)^{2}}{\sum_{i=1}^{n}\left(y_{i-} \hat{\mathrm{y}}_{i}\right)^{2}}$

Where yi is the in-situ measurement of water level. Lastly, accuracy was evaluated by using the linear regression (estimated value vs in-situ value). The values obtained by the two approaches be in seamless arrangement where regression has ' $\mathrm{R}^{2}$ ' equivalent to 1 , 'b' equal to 1 , and 'a' equal to 0 , as a degree of accuracy.

\section{Results And Discussion}

\subsection{Water surface area}

The results demonstrate that the reservoir's water surface area ranged from $1.781 \mathrm{Km}^{2}$ to $11.778 \mathrm{Km}^{2}$ between September 2016 and September 2019, and the in-situ observed water level ranged from 99.54 to $108.0 \mathrm{~m}$. Satellite-derived water surface area and level trends from 2016 to 2019 showed a consistent trend with the in-situ observation (Figure 4). The results acquired from satellite images are well correlated with the ground observation (Annor et al. 2009; Kaplan and Avdan 2017; Li et al. 2013; Lu et al. 2013; Ran and Lu 2012). The differences are reflected in the seasonal variations (Figure 5) and draw-ups triggered by heavy rainfall and seasonal monsoon rainfall (Figure 6) (Gu et al. 2021; Ran and Lu 2012).

Darawat watershed has indigenous topography of low, rocky mountain ranges separated by valleys. The topography, surface area, and water levels values coincided during January 2019 at a water level of 101 meters (Figure 4). It indicates the presence of near-flat surfaces and gentle topography, no significant change occurs in surface area as a water level decreases below 101 meters. While in the low rocky 
mountainous region, the reservoir surface area decreases prominently as the water level decreases (Wang et al. 2013; Zhou et al. 2020).

\subsection{Reservoir's Level-Area-Volume relationship}

The study results represented the significant relationship among the water surface area, level, and volume. However, these parameters have been acquired from satellite images, digital elevation models, and in-situ data. The linear, exponential, logarithmic, power and 2nd order polynomial models have been calculated for the relationship between surface area and water level. The relationships between surface area and water level range from 0.941 to 0.991 (Figure 7), surface area and volume range from 0.9283 to 0.9948 (Figure 8), and water level and volume ranges from 0.9433 to 0.9986 (Figure 9) are significant.

The power and the logarithmic models effectively described the significant relationship between the surface area and the water level. However, the polynomial of 2 nd order can also be of great importance in describing the relationship. Based on $\mathrm{R}^{2}$ values, the other two models are not suitable for describing the significant relationship (Figure 7).

The surface area and volume relationship demonstrated that the 2nd order polynomial, linear equation, and power model efficiently depict surface area and reservoir volume relationship (Figure 8). Other models represented insignificant relationships based on $\mathrm{R}^{2}$ values.

The Polynomial of 2nd order and the power equation efficiently defined the relationship between water level and reservoir volume. The exponential equation for the water level volume relationship is also a good fit. Other multiple models do not describe the significant relationship based on $\mathrm{R}^{2}$ values (Figure 9 ).

Visual variation is created by utilizing the equations (Table 1) and SRTM-DEM to estimate water surface area and level. However, the in-situ recorded the maximum water level at 108 meters above sea level (masl) that covered an area of $11.77 \mathrm{~km}^{2}$. Whereas the estimated water level at 109 masl covered $17.46 \mathrm{~km}^{2}$ area, at 110 masl covered $21.53 \mathrm{~km}^{2}$ area, at 111 masl covered $26.51 \mathrm{~km}^{2}$, and at 112 masl covered an area of $32.57 \mathrm{~km}^{2}$ (Figure 10).

Table 1

Quantitative assessment of different models' equations

\begin{tabular}{|lllll|}
\hline Name & Equation & $\mathbf{R}^{2}$ & RMSE (meter) & PD (\%) \\
\hline Exponential & $\mathrm{WL}=99.409 \mathrm{e}^{8 \mathrm{E}-09(\mathrm{~s})}$ & 0.994 & 0.8795 & 0.7347 \\
\hline Liner & $\mathrm{WL}=8 \mathrm{E}-09(\mathrm{~s})+99.33$ & 0.9942 & 0.8181 & 0.6314 \\
\hline Logarithmic & $\mathrm{WL}=4.4792 \ln (\mathrm{S})+34.799$ & 0.9807 & 0.2996 & 0.1537 \\
\hline 2nd Order Polynomial & $\mathrm{WL}=-6 \mathrm{E}-14 \mathrm{~S}^{2}+2 \mathrm{E}-06(\mathrm{~S})+97.323$ & 0.9949 & 1.7517 & 1.6146 \\
\hline Power & $\mathrm{WL}=53.373(\mathrm{~S})^{0.0432}$ & 0.9823 & 0.3359 & 0.2275 \\
\hline
\end{tabular}




\subsection{Validation}

The functions and equations of different models have been calculated to find out the relationships among level, area, and volume. However, various models depict different results based on the type of data and function used by a particular model. Further, results have been verified by utilizing satellite Landsat OLI images and WAPDA In-situ water level data. The equations derived from Landsat-OLI multispectral imageries showed a remarkable (PD ranged from 0.153 to $1.614, R^{2}$ ranged from 0.980 to 0.994, and RMSE ranged from $0.299 \mathrm{~m}$ to $1.75 \mathrm{~m}$ ) relationship among water levels of the reservoir and surface water area (Table 1 and Figure 11). Whereas computed from sentinel-2 images are consistent with the evaluation results of the Darawat storage (Figure 10). The value of $R^{2}$ of 2 nd order polynomial illustrates a high relationship between the two parameters. The RMSE of the same model, depicted as it compares with a predicted value as an observed or known value. All models showed a near-perfect relationship between surface area and water level. However, the logarithmic model relatively fits accurately with the dependent variable values. Further, the Power model followed by the logarithmic model can use with ease.

\section{Conclusion}

The appraisal from 2016 to 2019 of the reservoir water surface area by utilizing Landsat-8 (OLI) images and water levels acquired from In-situ for examining the relationship among reservoir's level-area-volume with the help of an exponential, linear, logarithmic, polynomial, and power models. Quantitative analysis and qualitative evaluation displayed that all models accepted the optimal relationship between surface areas and water levels of the reservoir. The derived equations from Landsat-OLI and Sentinel data showed a significant relationship between water levels and surface area and were consistent with the evaluation results of Darawat reservoir through in-situ. The PD (0.153), $\mathrm{R}^{2}$ (0.991), and RMSE (0.299) values of the Logarithmic model showed relatively beneficial as compared to other models. The study results suggest the models may utilize in water resource management, hydropower, environmental monitoring, and flood control.

\section{Declarations}

\section{Declaration of Competing Interest}

The authors declare that they have no known competing financial interest or personal relationships that could have appeared to influence the work reported in this paper

\section{Acknowledgment}

The authors would like to acknowledge the Water \& Power Development Authority South (WAPDA-South) for providing the daily water level of Darawat reservoir, USGS for Landsat images, Copernicus for Sentinel 
data, and the Climate Research Unit, the University of East Anglia, the United Kingdom for providing the meteorological data.

\section{Data availability}

All data generated or analysed during this study are included in this published article and its supplementary information files.

\section{References}

1. Alsdorf, D.E., Rodríguez, E., \& Lettenmaier, D.P. (2007). Measuring surface water from space. Reviews of Geophysics, 45

2. Annor, F.O., Van De Giesen, N., Liebe, J., Van de Zaag, P., Tilmant, A., \& Odai, S. (2009). Delineation of small reservoirs using radar imagery in a semi-arid environment: $A$ case study in the upper east region of Ghana. Physics and Chemistry of the Earth, Parts A/B/C, 34, 309-315

3. Begum, A., Ghalib, S.A., Khan, M.Z., Zehra, A., Khan, A.R., Hussain, B., \& Tabbassum, T.A.L.a.F. (2014). An overview of the current status and distribution of amphibians in Sindh. African Journal of Science and Research, 3, 21-23

4. Birkett, C.M., \& Beckley, B. (2010). Investigating the performance of the Jason-2/OSTM radar altimeter over lakes and reservoirs. Marine Geodesy, 33, 204-238

5. Brenner, A.C., DiMarzio, J.P., \& Zwally, H.J. (2007). Precision and accuracy of satellite radar and laser altimeter data over the continental ice sheets. IEEE Transactions on Geoscience and Remote Sensing, $45,321-331$

6. Calmant, S., Seyler, F., \& Cretaux, J.F. (2008). Monitoring continental surface waters by satellite altimetry. Surveys in geophysics, 29, 247-269

7. Crétaux, J.-F., \& Birkett, C. (2006). Lake studies from satellite radar altimetry. Comptes Rendus Geoscience, 338, 1098-1112

8. Du, Z., Li, W., Zhou, D., Tian, L., Ling, F., Wang, H., Gui, Y., \& Sun, B. (2014). Analysis of Landsat-8 OLI imagery for land surface water mapping. Remote sensing letters, 5, 672-681

9. Duan, Z., \& Bastiaanssen, W. (2013). Estimating water volume variations in lakes and reservoirs from four operational satellite altimetry databases and satellite imagery data. Remote Sensing of Environment, 134, 403-416

10. Enright, N., Miller, B., \& Akhter, R. (2005). Desert vegetation and vegetation-environment relationships in Kirthar National Park, Sindh, Pakistan. Journal of Arid Environments, 61, 397-418

11. Gu, Z., Zhang, Y., \& Fan, H. (2021). Mapping inter-and intra-annual dynamics in water surface area of the Tonle Sap Lake with Landsat time-series and water level data. Journal of Hydrology, 601, 126644

12. Haghiabi, A., Slamian, S., MOHAMMADZADEH, H.J., \& Mousavi, S. (2013). DERIVATION OF RESERVOIR'S AREA-CAPACITY EQUATIONS BASED ON THE SHAPE FACTOR, RESEARCH NOTE 
13. Jeppesen, E., Søndergaard, M., Jensen, H.S., \& Ventälä, A.-M. (2009). Lake and reservoir management. Encyclopedia of Inland waters (pp. 295-309): Pergamon Press

14. Ji, L., Zhang, L., \& Wylie, B. (2009). Analysis of dynamic thresholds for the normalized difference water index. Photogrammetric Engineering \& Remote Sensing, 75, 1307-1317

15. Kaplan, G., \& Avdan, U. (2017). Water extraction technique in mountainous areas from satellite images. Journal of Applied Remote Sensing, 11, 046002

16. Li, W., Du, Z., Ling, F., Zhou, D., Wang, H., Gui, Y., Sun, B., \& Zhang, X. (2013). A comparison of land surface water mapping using the normalized difference water index from TM, ETM+ and ALI. Remote Sensing, 5, 5530-5549

17. Ling, F., Cai, X., Li, W., Xiao, F., Li, X., \& Du, Y. (2012). Monitoring river discharge with remotely sensed imagery using river island area as an indicator. Journal of Applied Remote Sensing, 6, 063564

18. Lu, S., Ouyang, N., Wu, B., Wei, Y., \& Tesemma, Z. (2013). Lake water volume calculation with time series remote-sensing images. International Journal of Remote Sensing, 34, 7962-7973

19. Ouma, Y.O., \& Tateishi, R. (2006). A water index for rapid mapping of shoreline changes of five East African Rift Valley lakes: an empirical analysis using Landsat TM and ETM+ data. International Journal of Remote Sensing, 27, 3153-3181

20. Pipitone, C., Maltese, A., Dardanelli, G., Lo Brutto, M., \& La Loggia, G. (2018). Monitoring water surface and level of a reservoir using different remote sensing approaches and comparison with dam displacements evaluated via GNSS. Remote Sensing, 10, 71

21. Poolman, M.I. (2005). Developing small reservoirs: A participatory approach can help. In: Technical University Delft

22. Qureshi, M.A. (2010). Dam/reservoir sites selection using remote sensing \& GIS techniques. In, Bridging the Gap through Satellite Technology: Cairo, Egypt, ISNET/NARSS Seminar in EgyptAt: Cairo, Egypt

23. Ran, L., \& Lu, X. (2012). Delineation of reservoirs using remote sensing and their storage estimate: an example of the Yellow River basin, China. Hydrological Processes, 26, 1215-1229

24. Rodrigues, L.N., \& Liebe, J. (2013). Small reservoirs depth-area-volume relationships in Savannah Regions of Brazil and Ghana. Water Resources and Irrigation Management, 2, 1-10

25. Rodrigues, L.N., Sano, E.E., Steenhuis, T.S., \& Passo, D.P. (2012). Estimation of small reservoir storage capacities with remote sensing in the Brazilian Savannah Region. Water resources management, 26, $873-882$

26. Wang, L., Huang, J., Du, Y., Hu, Y., \& Han, P. (2013). Dynamic assessment of soil erosion risk using Landsat TM and HJ satellite data in Danjiangkou Reservoir area, China. Remote Sensing, 5, 38263848

27. Xu, H. (2006). Modification of normalised difference water index (NDWI) to enhance open water features in remotely sensed imagery. International Journal of Remote Sensing, 27, 3025-3033 
28. Zhang, H., Gorelick, S.M., Zimba, P.V., \& Zhang, X. (2017). A remote sensing method for estimating regional reservoir area and evaporative loss. Journal of Hydrology, 555, 213-227

29. Zheng, J., Ke, C.-Q., Shao, Z., \& Li, F. (2016). Monitoring changes in the water volume of Hulun Lake by integrating satellite altimetry data and Landsat images between 1992 and 2010. Journal of Applied Remote Sensing, 10, 016029

30. Zhou, Y., Qi, S.-C., Fan, G., Chen, M.-L., \& Zhou, J.-W. (2020). Topographic Effects on ThreeDimensional Slope Stability for Fluctuating Water Conditions Using Numerical Analysis. Water, 12, 615

31. Zhu, W., Jia, S., \& Lv, A. (2014). Monitoring the fluctuation of Lake Qinghai using multi-source remote sensing data. Remote Sensing, 6, 10457-10482

32. Zwally, H.J., Schutz, B., Abdalati, W., Abshire, J., Bentley, C., Brenner, A., Bufton, J., Dezio, J., Hancock, D., \& Harding, D. (2002). ICESat's laser measurements of polar ice, atmosphere, ocean, and land. Journal of Geodynamics, 34, 405-445

\section{Figures}

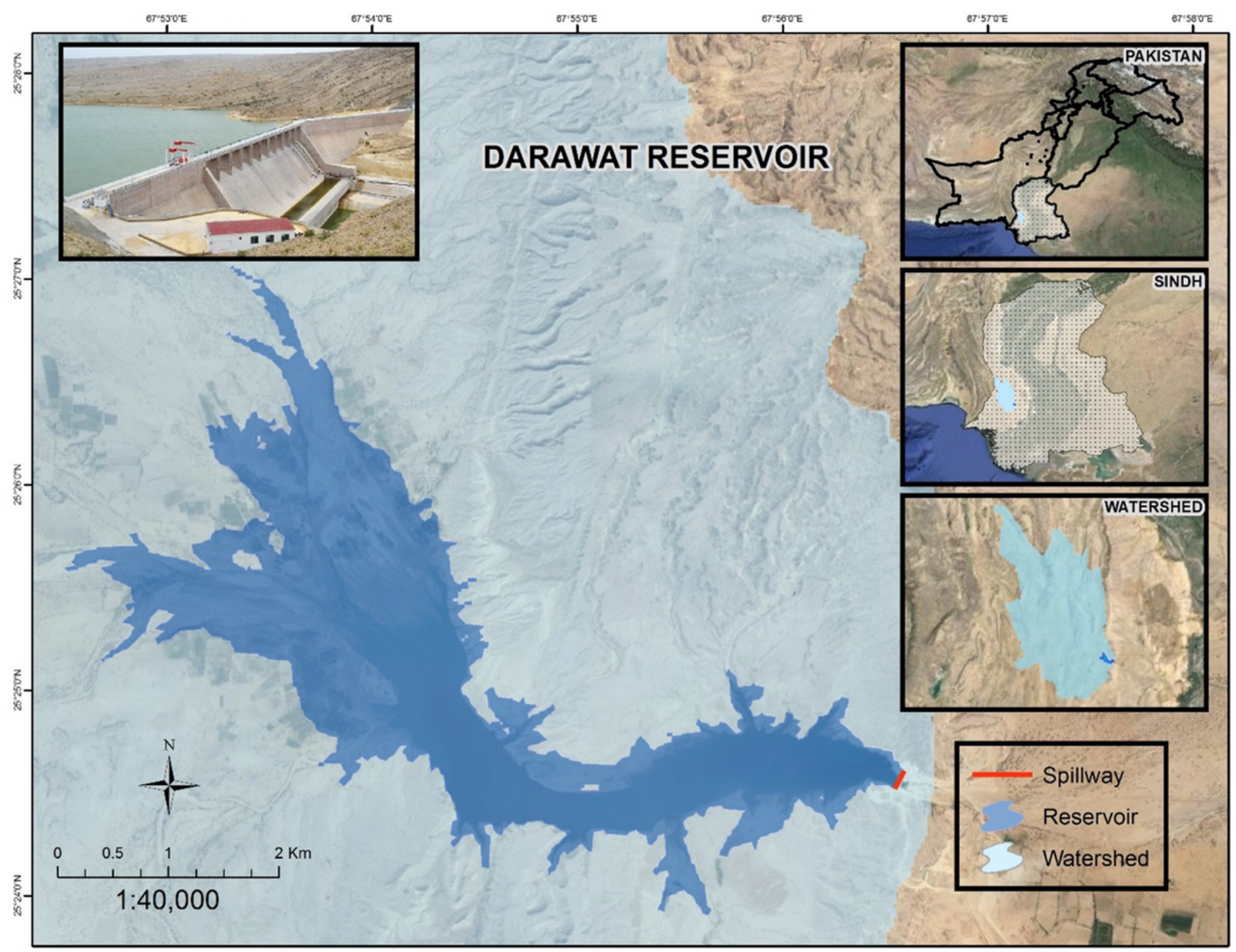


Figure 1

Watershed and reservoir extent of the study area
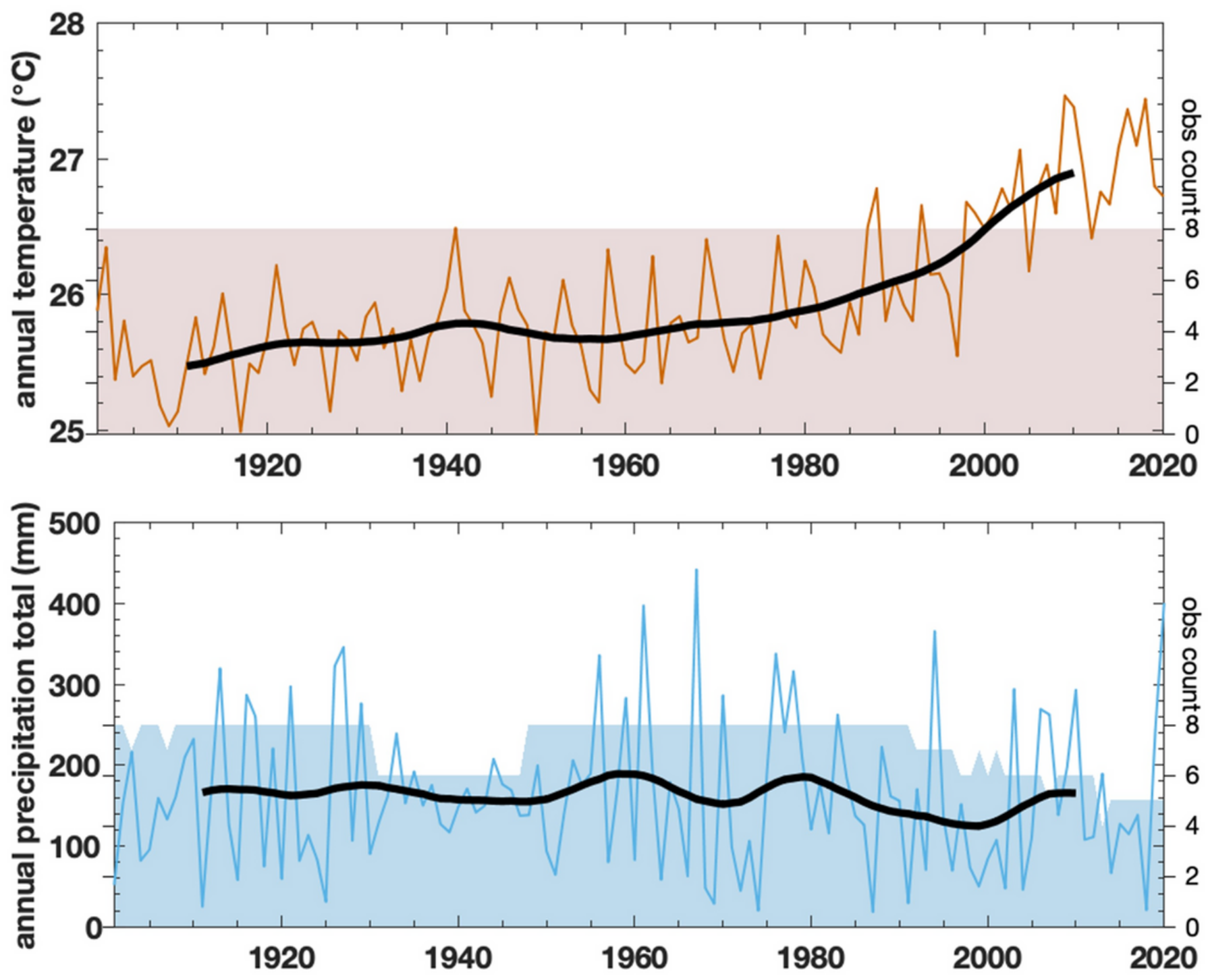

Figure 2

Annual precipitation and temperature acquired from CRU TS 4.04 grid-box of the study area. 


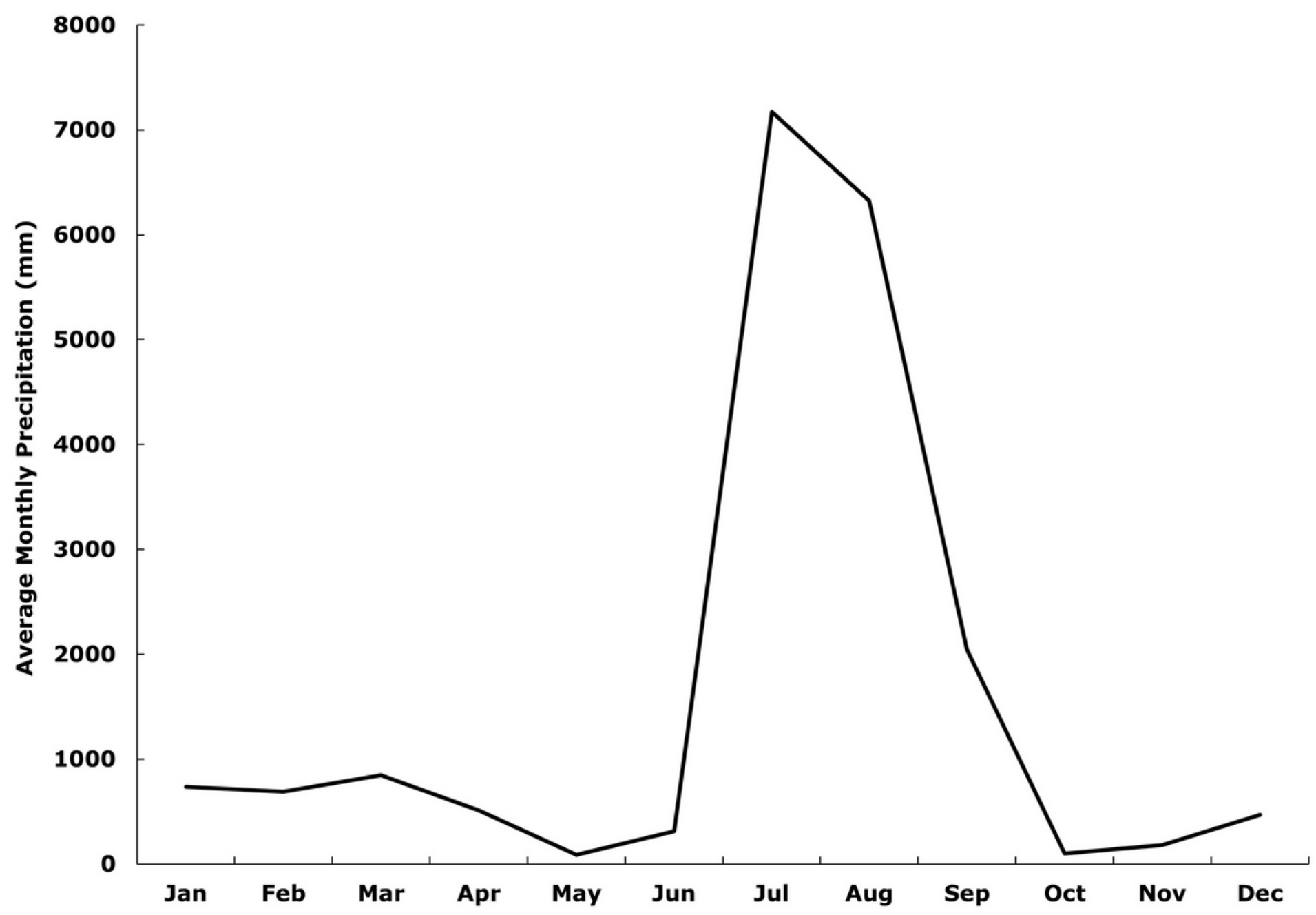

Figure 3

Average monthly precipitation from 1901-2019. 


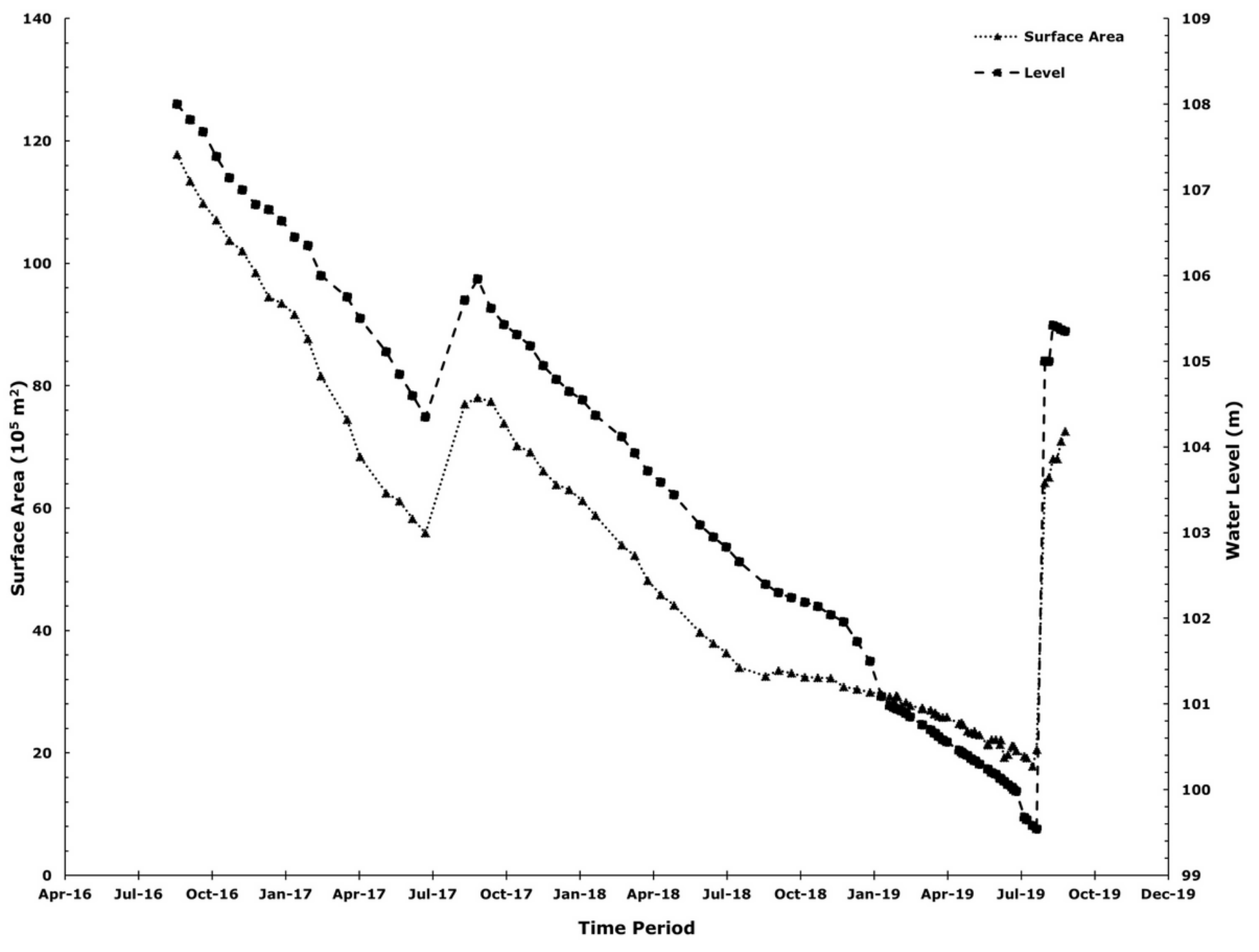

Figure 4

Changes in the water surface area and level from 2016 to 2019. 


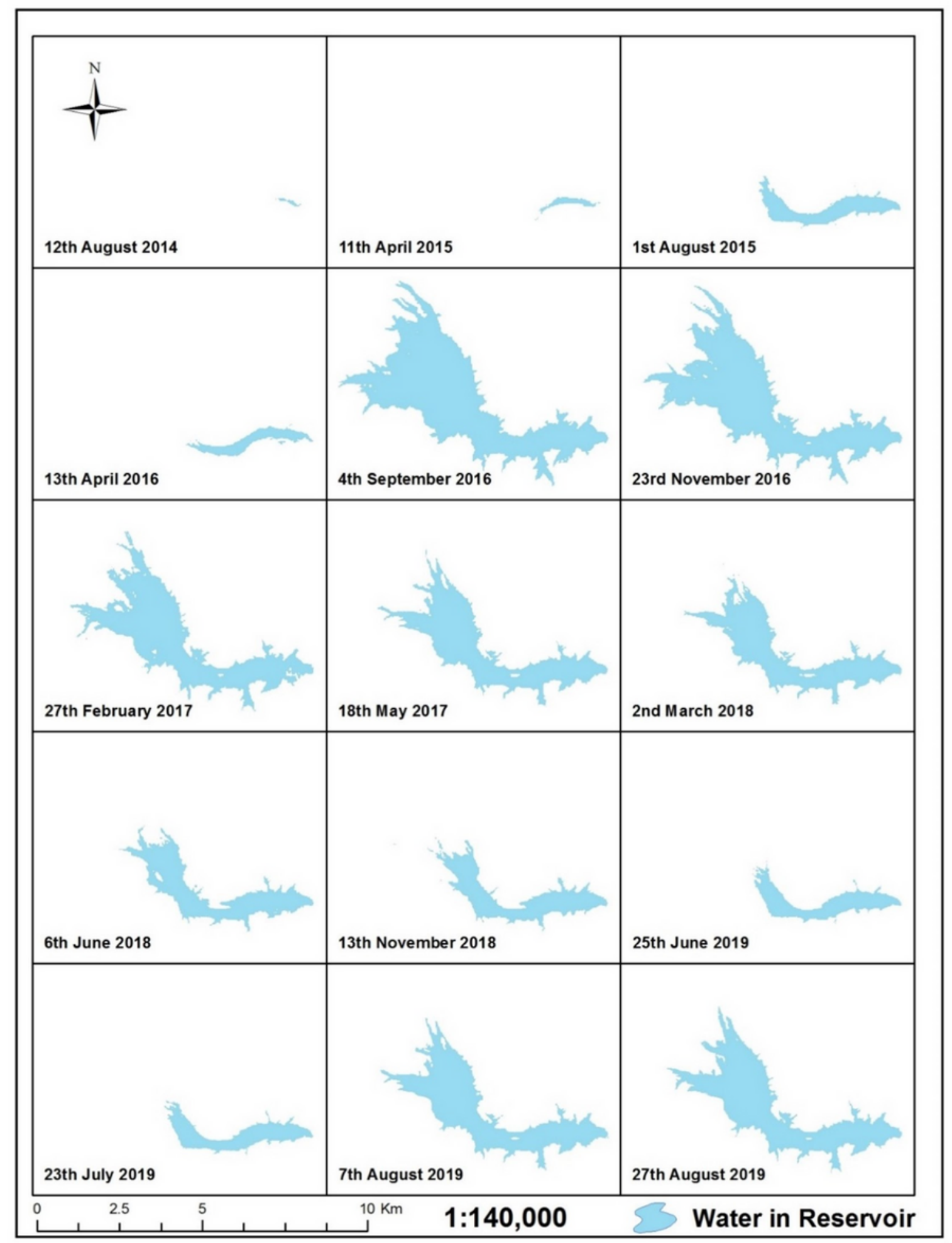

Figure 5

Water surface area variation from 2014 to 2019. 


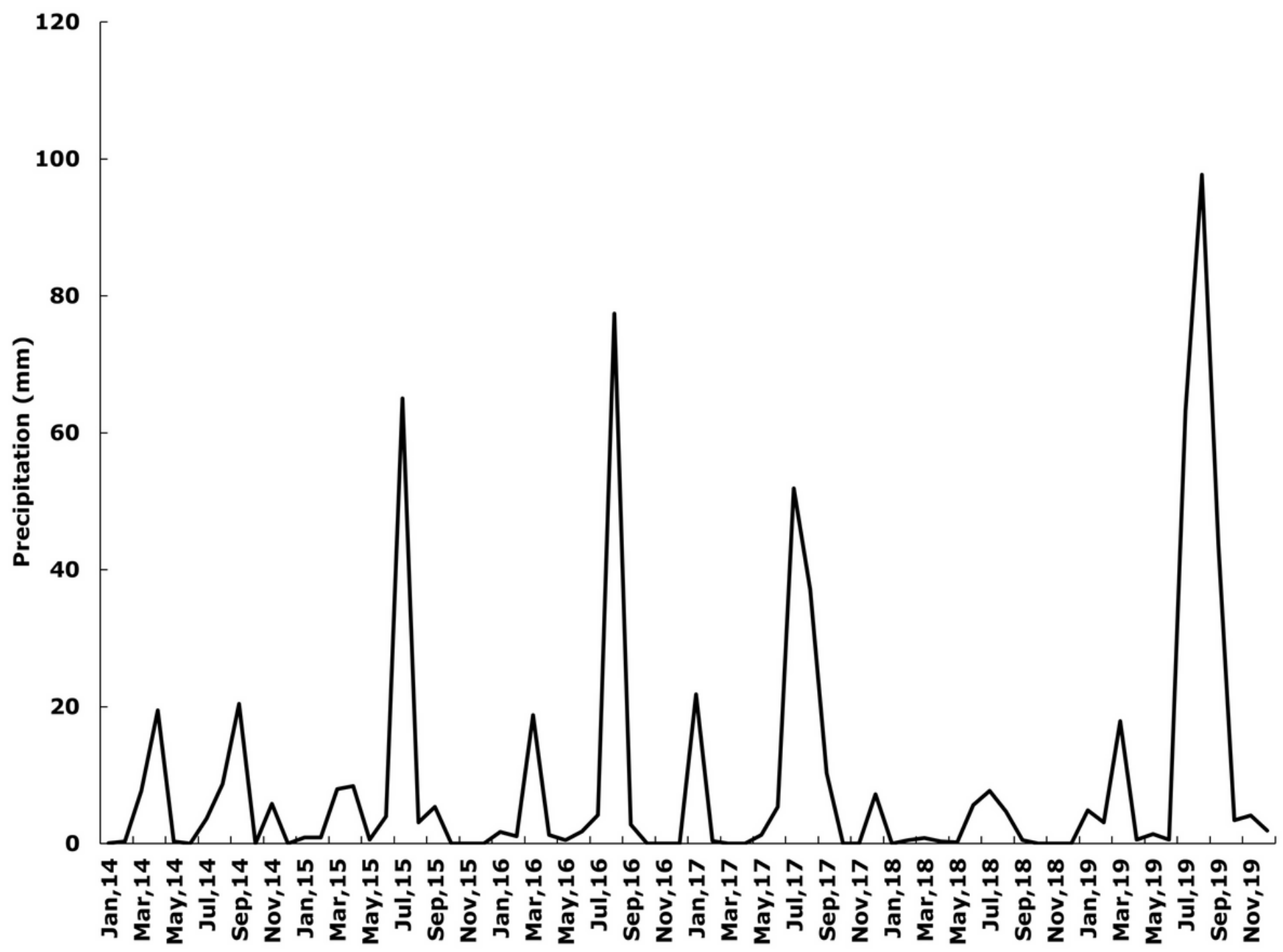

Figure 6

Monthly precipitation from January 2017 to December 2019 

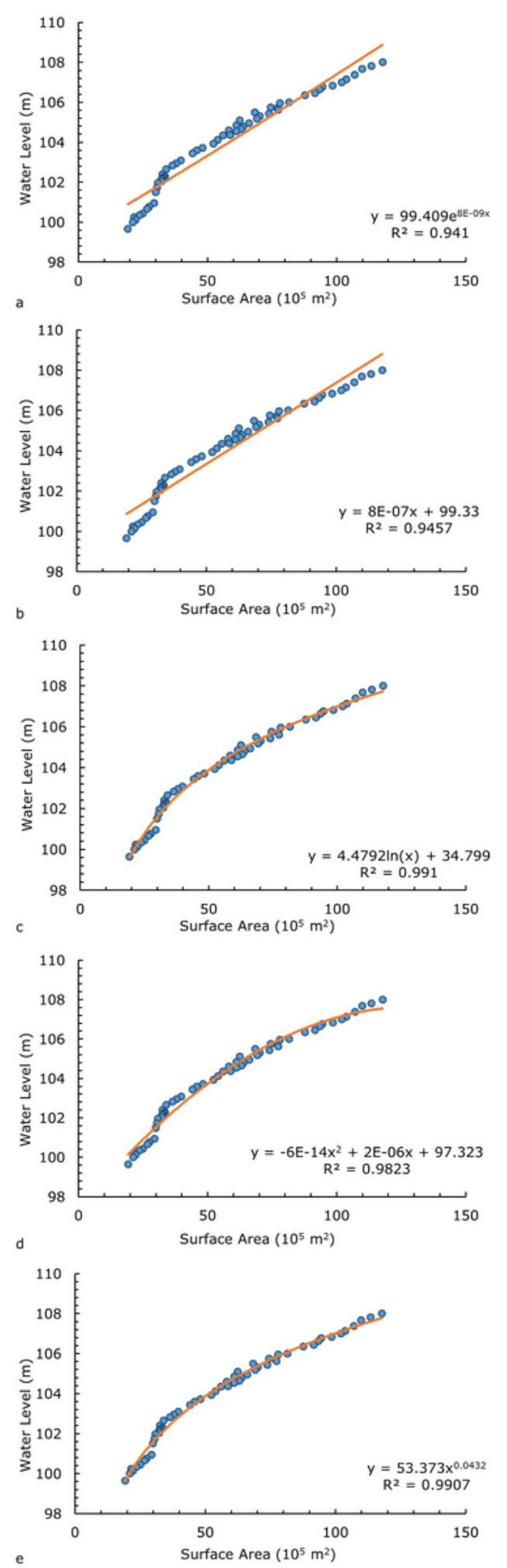

\section{Figure 7}

Relationship between the surface area and water level a) Exponential, b) Linear, c) Logarithmic, d) $2^{\text {nd }}$ Order polynomial, and e) Power model. 

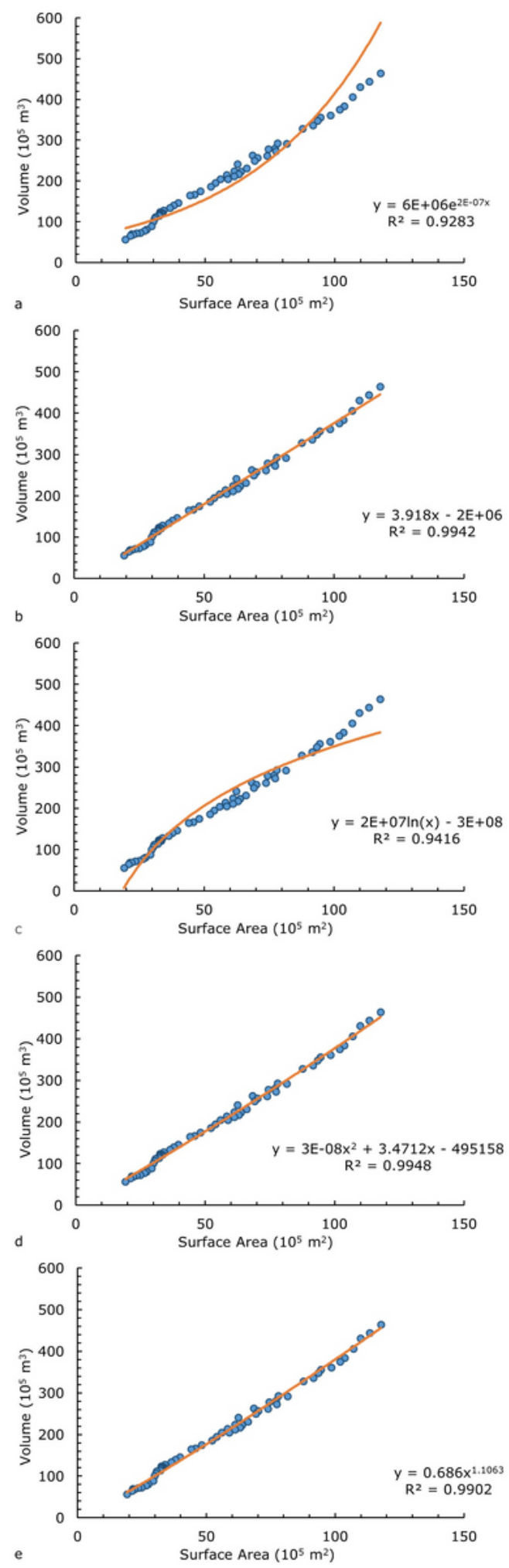

\section{Figure 8}

Relationship between the surface area and volume a) Exponential, b) Linear, c) Logarithmic, d) $2^{\text {nd }}$ Order polynomial, and e) Power model. 

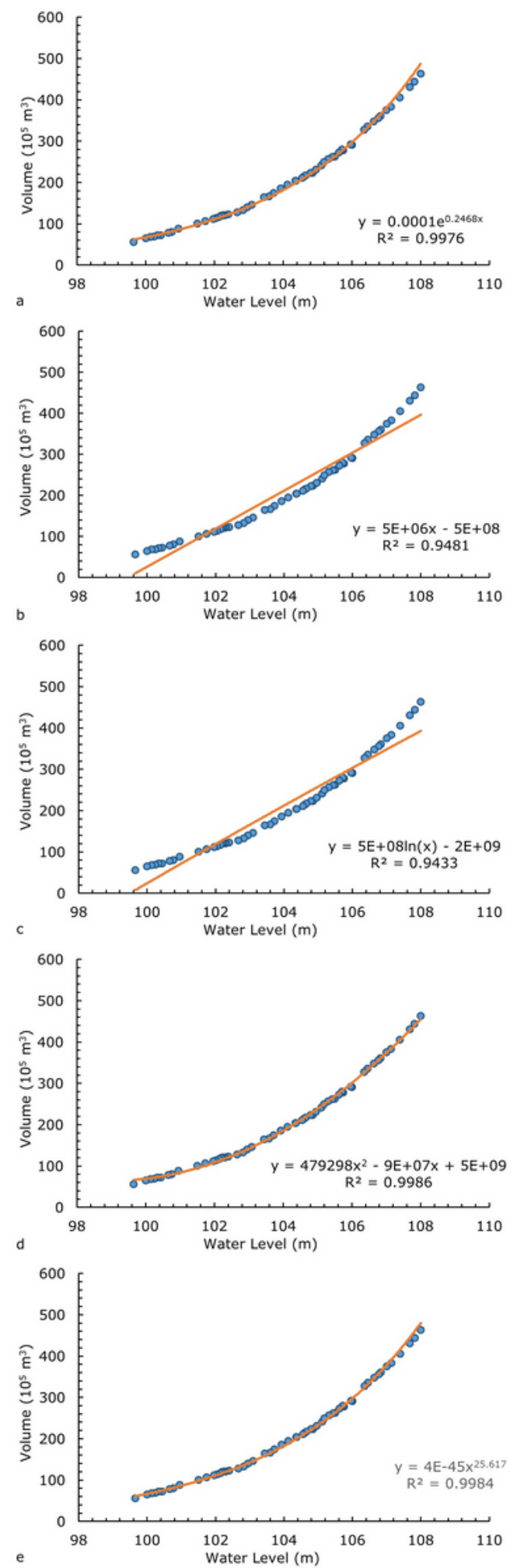

Figure 9

Relationship between the water level and volume a) Exponential, b) Linear, c) Logarithmic, d) $2^{\text {nd }}$ Order polynomial, and e) Power model. 

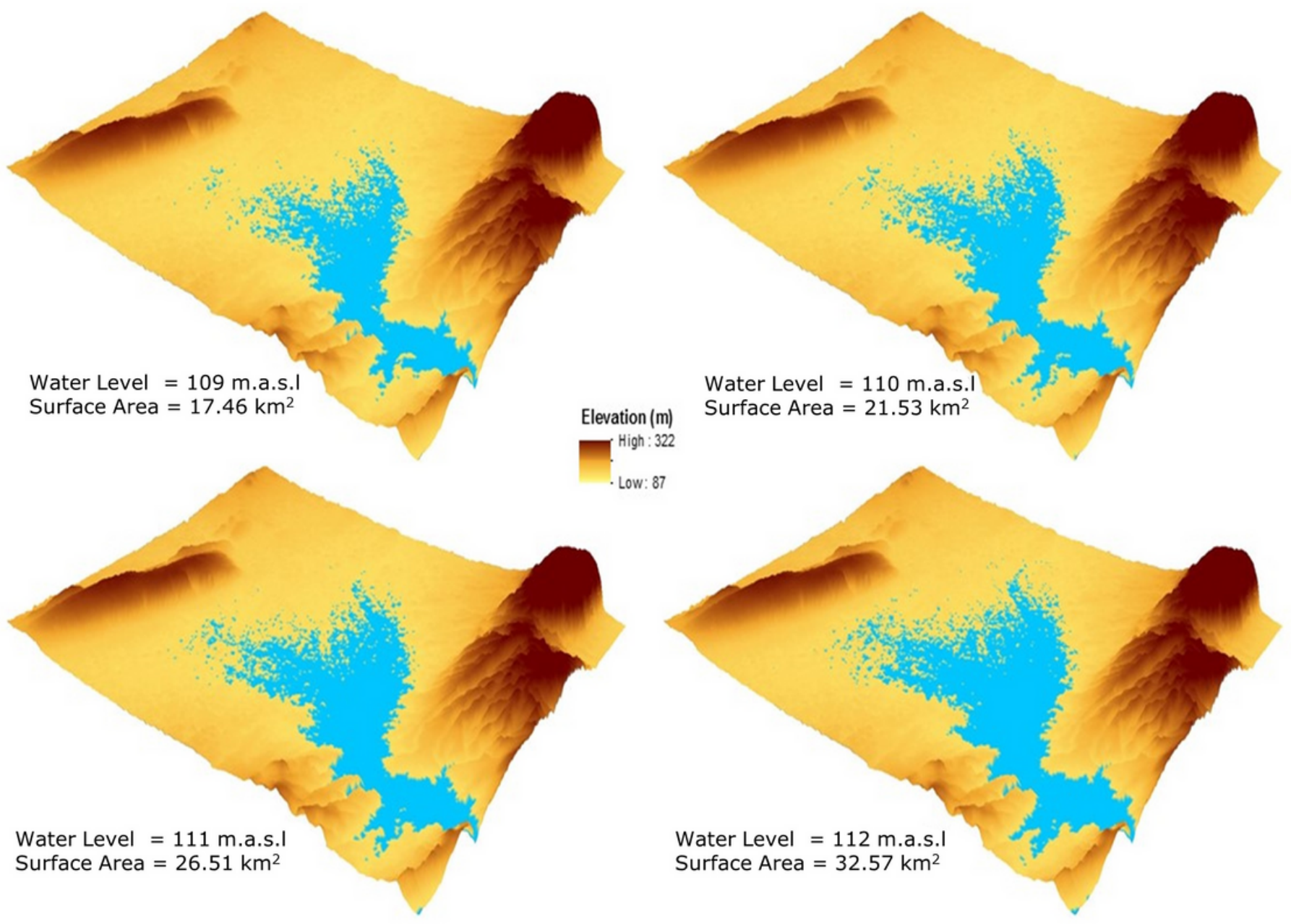

\section{Figure 10}

Estimated increase of water surface area with respect to reservoir water level. 

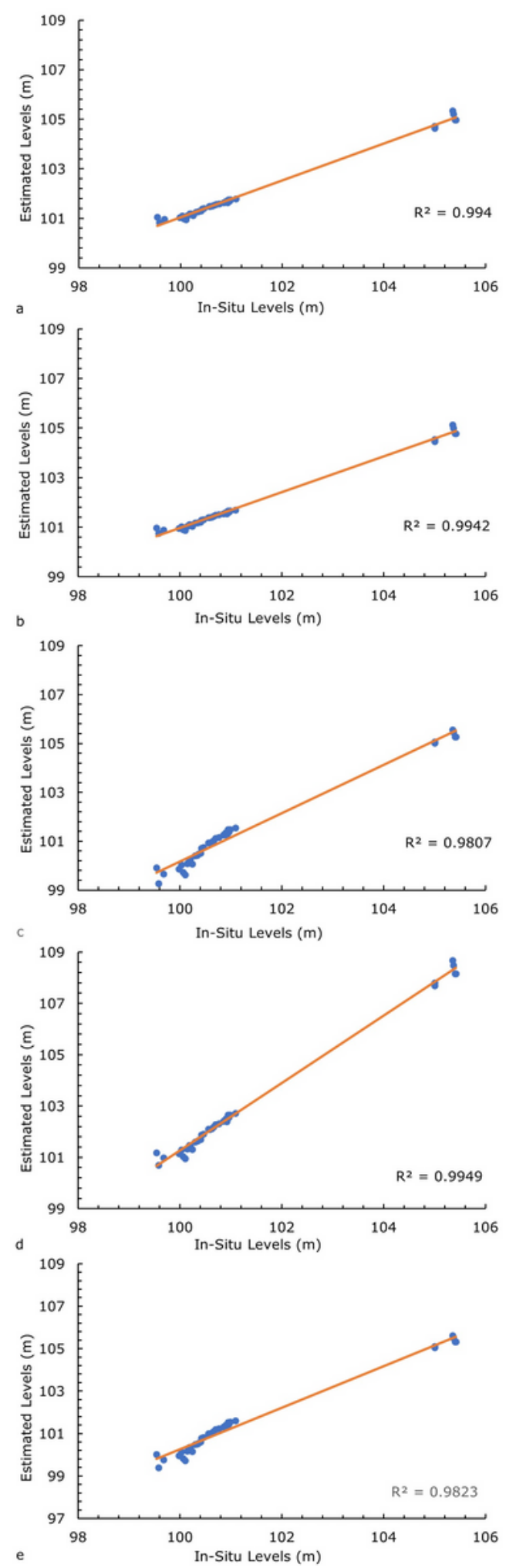

\section{Figure 11}

In-situ vs Estimated Water Levels derived by using Sentinel 2 satellite data a) Exponential, b) Linear, c) Logarithmic, d) $2^{\text {nd }}$ Order polynomial, and e) Power model. 